\title{
3D-Printed, Non-assembly, Pneumatically Actuated Mechanisms from Thermoplastic Materials
}

\begin{abstract}
AURELIAN ZAPCIU, CATALIN GHEORGHE AMZA*, CORNELIU RONTESCU, GABRIEL TASCA
Politehnica University of Bucharest, 313 Splaiul Independentei, 060042, Bucharest, Romania

Various applications in industry and medicine require the transmission of movement using systems that do not influence magnetic or electromagnetic fields. These components include systems which transmit linear or rotational motion, change position (switches), attach or detach to objects (latches), grip objects, etc. This paper looks into the possibility of producing such mechanisms using FDM 3D-printed parts from thermoplastic materials with embedded moving parts, which can be pneumatically actuated. In order to make the parts suitable for use in pressurized air systems, different sets of printing parameters have been investigated. PLA annealing is used in the attempt to minimize play and increase air-tightness of 3D-printed parts.
\end{abstract}

Keywords: FDM 3D printing, pneumatic mechanism, PLA annealing

One of the main aspects of automation is the control of moving parts (translation, rotation, and actuation). In certain applications, such as in medical research or medical investigation procedures, sensor testing, RF testing, fundamental physics research, etc., where movement needs to be transmitted close to equipment sensitive to magnetic and electromagnetic fields, the metal components predominantly used in the automation industry can interfere with critical process elements. For example, in medicine, biopsy used in cancer diagnosis of breast and prostate cancers can be performed with higher precision if guided by a magnetic resonance procedure [ 1 , 2]. In this case, if robotic systems are needed to assist or perform the biopsy and movement needs to be transmitted inside the powerful magnetic field of an MRI machine, metal components cannotbe used in the movement transmission mechanism.

In fundamental physics research, there are experiments where the accurate determination of magnetic or electromagnetic fields and their interactions is required metal parts would interfere with these fields and represent additional error sources.

A potential solution to these problems is the development of systems made out of non-metallic parts, actuated through a pneumatic or hydraulic system. Cheap, widely available and easily processed, plastic materials seem to be a suitable candidate for the job. However, making plastic parts in small batch production carries a large cost if it is done using traditional injection molding. Additive manufacturing is a better way to manufacture small batch or unique parts.

This paper presents the design and prototyping of several 3D-printable mechanisms which are designed to be pneumatically actuated, as a potentially cheaper and more widely accessible alternative to existing solutions. The prototypes are fabricated from thermoplastic materials using Fused Deposition Modeling (FDM) on various commercially available 3D printers.

In order to make the parts suitable for use in pressurized air systems, differentsets of printing parameters have been investigated $[3,4]$.

\section{Experimental part}

a. Design considerations and printing process parameters

In order to function in a pneumatic system, the pressurized surfaces of the components need to be airtight. For this reason, the inner walls of these parts should be fabricated using an increased material flow (over extrusion), or with an increased number of outside perimeters. The outer perimeters are kept at normal extrusion rates in order to not cause any plastic accumulation which might impair the function of the part. Overhanging surfaces are fabricated using a rectangular infill pattern with cooling fans providing maximum airflow in order to quickly cool down the extruded material to prevent sagging.

To prevent unwanted adhesion of the superior layer over an embedded moving part, layer adhesion is reduced using a method that uses the deposition of a layer of silicone oil between the layers of thermoplastic (fig. 1). The silicone oil layer lowers the surface of fused material and enables

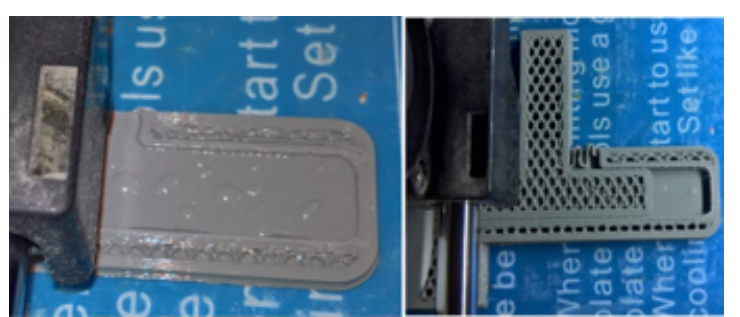

Fig. 1. Deposition of a layer of silicone oil to inhibit layer adhesion of $3 \mathrm{D}$ printed components which require separation after fabrication

freeing the joint easier after fabrication [5]. Other methods of lowering surface adhesion such as lowering surface area or increasing surface gap between parts are not applicable to parts intended to be used in pneumatic applications.

After the additive manufacturing process has ended, the parts are let to cool down to room temperature. Then the embedded moving parts are freed if necessary using mechanical force.

\section{b. Double acting pneumatic gripper}

A mechanism for a double acting pneumatic gripper has been designed, consisting in a fixed outer shell which 
is connected to a fixed gripper finger, and an inner moving part which is connected to a mobile finger (fig. 1). At the top of the part, on each side of the sliding finger, holes for the insertion of pneumatic fittings are found. Mechanism footprint is $72 \mathrm{~mm} \times 25 \mathrm{~mm} \times 14 \mathrm{~mm}$ ( $\mathrm{L} * \mid * h$ ) not including pneumatic fittings and the gripper opening is $15 \mathrm{~mm}$. When pressurized, the mobile finger acts as a pneumatic piston and slides in the direction opposite the chamber air pressure is supplied to. Clearances are 0.13 to $0.20 \mathrm{~mm}$ for the lower and upper horizontal surfaces and $0.2 \ldots 0.4 \mathrm{~mm}$ for vertical walls (fig. 2). Several sample components have been fabricated using FDM. Parts use a $0.2 \mathrm{~mm}$ layer height and multiple materials have been tested. Silicone oil deposition has been used during the printing process to reduce layer adhesion between parts which need to be separated. After the additive manufacturing process is completed and the prototype cools down, force is applied to the gripper's mobile finger, breaking off any fused connection with the body of the gripper and allowing it to slide freely. Table 1 presents the materials used during testing and the minimum clearances which allowed the parts to function correctly after fabrication.

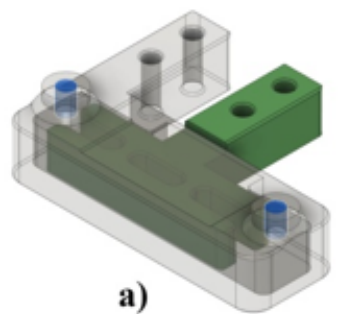

a)

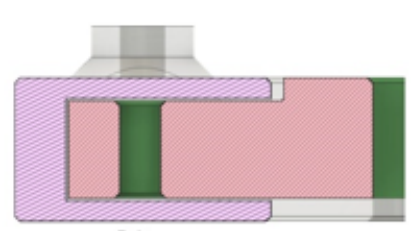

b)

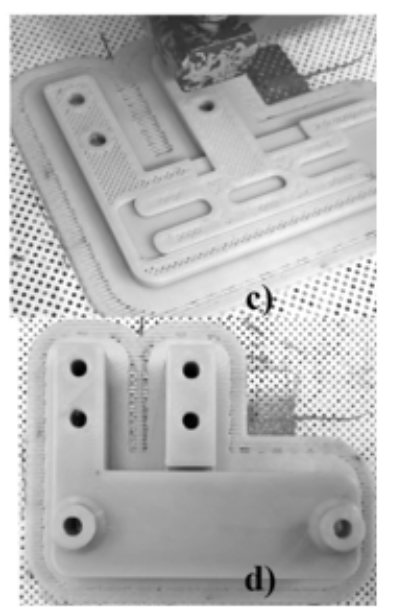

Fig. 2. 3D printed pneumatic gripper: a) 3D CAD model of pneumatic gripper; b) section view of the pneumatic gripper showing clearances; c) FDM printing process; d) finished pneumatic gripper prototype
The gripper mechanism has been used as the base for investigating differentsets of parameters for their capability of creating airtight printed surfaces. Multiple samples have been fabricated from PLA material. For vertical surfaces, parameter variation was used in the case of layer height $(0.15 \mathrm{~mm}$ to $0.25 \mathrm{~mm}$ ), printing temperature (200 to 220 $\left.{ }^{\circ} \mathrm{C}\right)$, extrusion flow (95 to 105\%) and number of perimeters used to create walls (2 to 4), (fig. 3.a), while extrusion flow and path overlap were considered for horizontal surfaces (fig. 3.b). Clearances have been maintained constant at $0.2 \mathrm{~mm}$ in the vertical plane and $0.4 \mathrm{~mm}$ in the horizontal plane.

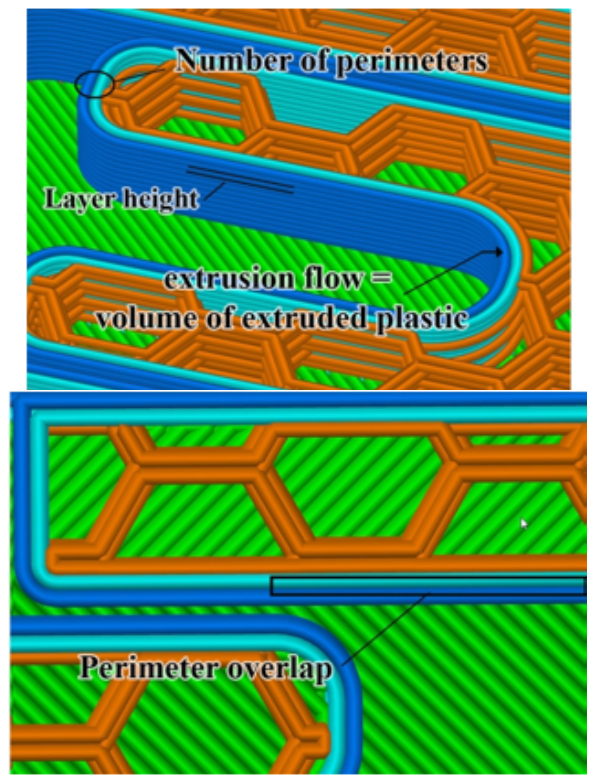

Fig. 3. Printing parameters for airtight pneumatic mechanisms

The results were tested by connecting the 3D-printed parts to a compressor and one 5/2-way valve. The system was pressurized to 6 bar, which is a pressure level commonly used in industrial pneumatic applications. The compressed air supply was cut off and the 5/2-way valve was repeatedly triggered and released, causing the gripper to close and reopen. The number of times the gripper successfully closes before pressure becomes insufficient due to leaks has been recorded.

For the five best performing sets of parameters, a subsequent test measured the gripping force of the printed parts at a constant pressure of 6 bar.

Table 1

PNEUMATIC GRIPPER PROTOTYPE - MINIMUM CLEARANCES

\begin{tabular}{|c|c|c|c|c|c|}
\hline 3D Printer & $\begin{array}{c}\text { Material, } \\
\text { producer }\end{array}$ & $\begin{array}{c}\text { Layer height } \\
{[\mathrm{mm}]}\end{array}$ & $\begin{array}{c}\text { Horizontal clearance } \\
{[\mathrm{mm}]}\end{array}$ & $\begin{array}{c}\text { Vertical Clearance } \\
{[\mathrm{mm}]}\end{array}$ & Post-Processing \\
\hline $\begin{array}{c}\text { Flashforge } \\
\text { Dual }\end{array}$ & $\begin{array}{c}\text { PLA, } \\
\text { Filamentum }\end{array}$ & 0.2 & 0.4 & 0.20 & Annealing \\
\hline $\begin{array}{c}\text { Flashforge } \\
\text { Dual }\end{array}$ & $\begin{array}{c}\text { ABS, Prima } \\
\text { Filaments }\end{array}$ & 0.2 & 0.25 & 0.20 & - \\
\hline $\begin{array}{c}\text { Creality Ender } \\
3\end{array}$ & $\begin{array}{c}\text { PLA, } \\
\text { Filamentum }\end{array}$ & 0.2 & 0.4 & 0.20 & Annealing \\
\hline $\begin{array}{c}\text { Zortrax M200 } \\
\text { ULTRAT, } \\
\text { Zortrax }\end{array}$ & 0.19 & 0.2 & 0.13 & - \\
\hline Zortrax M200 & $\begin{array}{c}\text { ABS-PC, } \\
\text { Zortrax }\end{array}$ & 0.19 & 0.20 & 0.13 & - \\
\hline
\end{tabular}

Table 2

PARAMETER SETS TESTING FOR AIRTIGHTNESS

\begin{tabular}{|c|c|c|c|c|c|c|}
\hline No. & $\begin{array}{c}\text { Perimeter } \\
\text { walls }\end{array}$ & $\begin{array}{c}\text { Layer height } \\
{[\mathrm{mm}]}\end{array}$ & $\begin{array}{c}\text { Printing } \\
\text { temp. }\left[{ }^{\circ} \mathrm{C}\right]\end{array}$ & Extrusion flow [\%] & No. of closing cycles & $\begin{array}{c}\text { Gripping force at 6 bar } \\
{[\mathrm{N}]}\end{array}$ \\
\hline 1 & 4 & 0.15 & 215 & 105 & 5 & 21.8 \\
\hline 2 & 3 & 0.15 & 215 & 105 & 4 & 18.9 \\
\hline 3 & 4 & 0.15 & 220 & 100 & 4 & 19.1 \\
\hline 4 & 4 & 0.20 & 215 & 105 & 4 & 17.3 \\
\hline 5 & 4 & 0.20 & 210 & 105 & 3 & 16.5 \\
\hline
\end{tabular}


It was observed that higher printing temperatures for PLA produce better airtight parts. However, if intending to manufacture parts with embedded moving joints, too high of a temperature can produce surface defects such as material accumulation or plastic stringing. Parts manufactured with high extrusion flow and high extrusion temperature $\left(105 \%, 220^{\circ} \mathrm{C}\right)$ jammed more often than parts manufactured with a moderately high temperature (215 $\left.{ }^{\circ} \mathrm{C}\right)$. A high number of perimeters reduces leakage through vertical pressurized surfaces. For horizontal surfaces, it is recommended that sufficient extrusion flow and extrusion overlap is used.

\section{c. Rotating pneumatic motor}

A mechanism which outputs a rotating motion through a shaft has been designed and 3D-printed (fig. 4.a). The mechanism, consisting in an outer stator uses air flow to rotate an inner rotor. Two holes for mounting pneumatic fittings are located on the side of the device. The mechanism can be actuated using an air pump or a compressor, at a pressure from 4 bar to 8 bar. Due to the geometry of the mechanism, the device can execute continuous or intermittent rotational movement in a single direction. A clearance of $0.25 \mathrm{~mm}$ was used for vertical and inclined walls, with a $0.40 \mathrm{~mm}$ clearance used for horizontal surfaces (fig. 4.b). Silicone oil was applied to the flat surface onto which the base of the rotor was deposited. Following fabrication on an FDM printer (fig. 4.c),

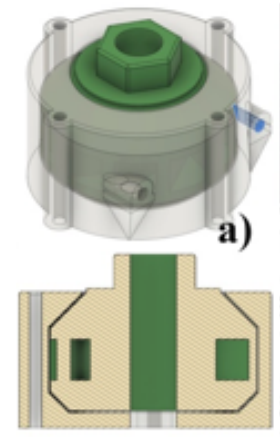

b)

a)
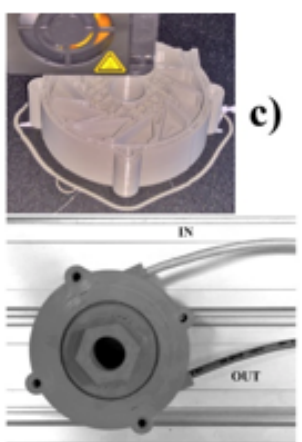

d)
Fig. 4. Rotational pneumatic mechanism: a) 3D model of pneumatic rotational mechanism; b) section view of the mechanism showing part clearances; c) manufacturing the mechanism through FDM; 3D

printed prototype of a pneumatic rotational mechanism

torque was applied to the hexagonal output shaft and the rotor was successfully detached from the stator.

d. Three jaw power chuck

Useful in applications that require gripping and securing a cylindrical part during motion, a chuck with three jaws has been designed and fabricated (fig. 2.a). Internal air ducts are used to connect a pressurization system to the

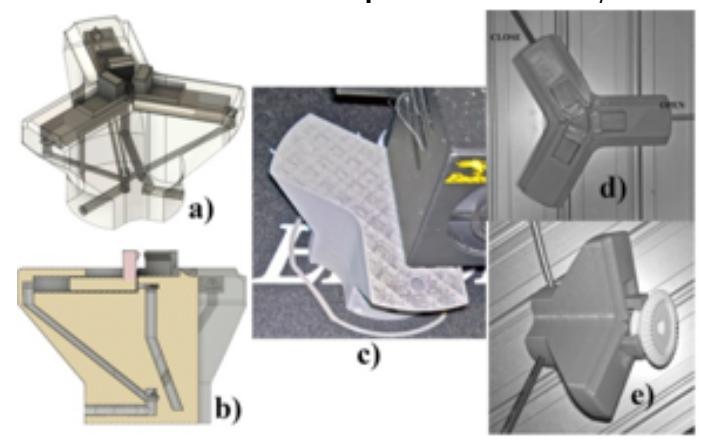

Fig. 5. 3D printed pneumatic chuck mechanism: a) 3D model of

3-jawed chuck mechanism; b) section view of the mechanism showing part clearance and internal air ducts; c) manufacturing the mechanism through FDM; d) top view of the 3D printed prototype;

e) actuated chuck mechanism gripping a cylindrical surface chuck jaws, which act as pneumatic piston when the chamber is pressurized (fig. 5.b). The volume of their corresponding chamber plus the volume of the internal air ducts is designed to be equal for all the jaws, ensuring simultaneous closing of the three jaws. The device can be controlled through a 5/2-way valve, with one line connected to the intake which forces the jaws shut when pressurized, and another line connected to an output port which releases pressure from the center of the chuck, allowing the retained part to be freed.

e. Latching mechanism

A pneumatic latching mechanism similar to those used in CNC tool changing has been designed and fabricated [Figure 6.a]. The prototype is $50 \times 38 \mathrm{~mm}\left(D^{*} \mathrm{~h}\right)$ and accommodates a $25 \mathrm{~mm}$ shaft. The mechanism composed of a fixed main body and 3 linear moving pins can be pneumatically actuated through a 3/2-way valve. A set of internal air ducts with identical volume connect the pneumatic system to chamber which contains the pins. When pressure is applied through the intake port, the 3 pins act as pneumatic pistons and pivot towards the center of the part (fig. 6.c), locking a cylindrical shaft in place. When pressure is released, the pins are free to slide back, unlocking the center shaft. The locking pins are manufactured in a $45^{\circ}$ inclined position relative to the $Z$ axis. Minimum clearances when the mechanism is fabricated from PLA are $0.25 \mathrm{~mm}$ in all axis. A slightly higher than usual thermoplastic material fusion is desired due to the orientation of the mobile part at an angle. After fabl usir
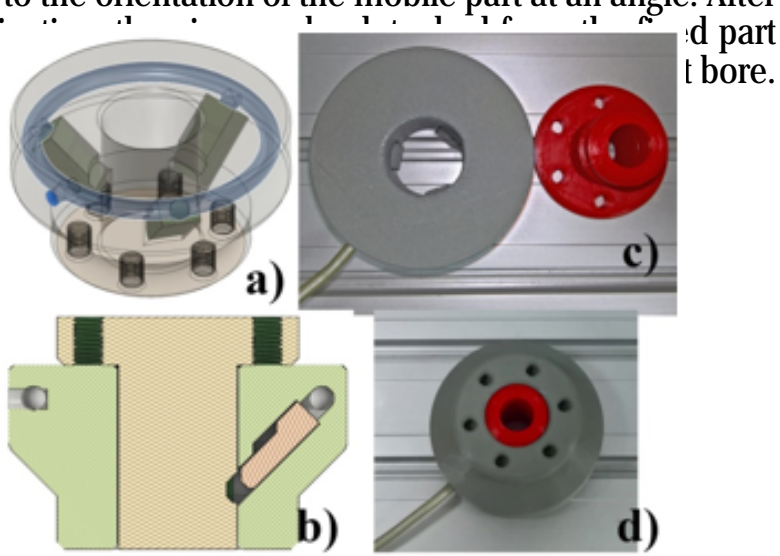

Fig. 6. 3D printed pneumatic latching mechanism: a) 3D model of pneumatic latching mechanism; b) section view of model which shows part clearances; c) latching mechanism with pins in locked position; d) latching mechanism with retained shaft.

\section{Results and discussions}

Annealing as a means of reducing clearances and improving partfunction

PLA annealing is a well-documented process in the case of injection-molded parts [6, 7] and lately approached by researchers in the case of 3D-printed parts. After injection molding or 3D printing process is finished, PLA parts are heated at a temperature between 60 and $80^{\circ} \mathrm{C}$ and then slowly cooled to room temperature. This process increases the strength of the material and its temperature resistance, while causing a slight shrinkage of the part [8]. In the case of 3D printed parts, due to their anisotropic character, dimensional changes vary with direction. In the horizontal plane (layer plane) PLA parts can shrink by 3$5 \%$ while in the vertical plane (part height) there is a dimensional increase of up to $2 \%$ [9].

In our experiments we attempt to exploit the characteristics of the annealing process to reduce play in parts with embedded moving joints fabricated through FDM 


\begin{tabular}{|c|c|c|c|c|c|c|}
\hline \multirow{2}{*}{ Sample No. } & \multirow{2}{*}{$\begin{array}{c}\text { Time at } 70 \\
{ }^{\circ} \mathrm{C}\end{array}$} & \multicolumn{3}{|c|}{ Dimensional change $[\%]$} & \multirow{2}{*}{$\begin{array}{l}\text { No. of closing } \\
\text { cycles }\end{array}$} & \multirow{2}{*}{$\begin{array}{c}\text { Mechanism status after heat } \\
\text { treatment }\end{array}$} \\
\hline & & $\mathrm{X}$ & $\mathrm{Y}$ & $\mathrm{Z}$ & & \\
\hline Gripper 1 & 2 hours & -0.9 & -1.1 & +0.1 & 7 & Function improved \\
\hline Gripper 2 & 2 hours & -0.7 & -1.1 & 0 & 7 & Function improved \\
\hline Gripper 3 & 4 hours & -1.4 & -1.8 & +0.4 & 8 & Function improved \\
\hline Gripper 4 & 4 hours & -1.7 & -2 & +0.3 & 1 & Function partially impaired \\
\hline Gripper 5 & 6 hours & -2.6 & -2.5 & +1.2 & 0 & Jammed \\
\hline Chuck & 2 hours & -0.8 & -0.9 & +0.3 & - & Function improved \\
\hline Latch & 2 hours & -1 & -1 & +0.2 & - & Function improved \\
\hline Rotational & 2 hours & -1.5 & -1.4 & +0.2 & - & Jammed \\
\hline
\end{tabular}

Table 3 DIMENSIONS OF THE 3D-PRINTED PARTS
3D-printing and to further improve the air-tightness of the part for pneumatic applications.

A number of 5 PLA test parts of the gripper mechanism, as well as the other types of mechanisms discussed previously were introduced in an oven and heated to $70^{\circ} \mathrm{C}$. The gripper mechanisms were removed from the oven after different periods of time, while the other mechanisms were removed after $2 \mathrm{~h}$. Dimensions of the 3D-printed parts were measured before and after the heat treatment using digital calipers. Pressure testing was repeated for the gripper mechanism samples.

\section{Conclusions}

This paper looks into the use 3D-printed mechanisms made out of thermoplastic material in pneumatic systems. FDM printed parts are a challenge to implement in functional products which require a certain degree of precision, such as pneumatic mechanisms. The main challenge when creating parts with precise features is dealing with the inevitable process variability which can stem from part slicing limitations, machine precision limitations, process parameter variability (temperature variations) or raw material variability (filament diameter, composition).

Multiple sets of parameters have been assessed in the attempt of establishing a process which can be used to reliably create airtight parts to be used in pneumatic systems.

For the specific type of thermoplastic filament used for testing (Concrete Grey PLA Extrafill by Filamentum), which specifies recommended extrusion temperatures of $190^{\circ} \mathrm{C}$ to $210^{\circ} \mathrm{C}$, printing on the upper end of the scale and even hotter has improved layer adhesion and reduced leakage in pressurized parts. At extrusion temperatures above $220^{\circ} \mathrm{C}$ stringing and blobs of material can impact part function.

Number of perimeters used to construct airtight walls should be a minimum of 3 for a machine which uses a 0.4 $\mathrm{mm}$ diameter nozzle. If the part is not airtight despite using the correct temperature and perimeter number, then a combination of perimeter overlapping and increased extrusion flow can be a solution. Higher overlapping and extrusion flow percentages should be used to construct horizontal surfaces.

PLA annealing has been used with a reasonable amount of success to reduce prototype clearances resulting in improved airtightness and function. Further work is needed in determining correct process parameters for annealing, specifically, temperature and treatment duration. In this way, one can achieve specific mechanical characteristics such as improved tensile, compression strength and impact energy absobtion [10]. Annealed 3D-printed parts also display slight distortions due to heterogeneous distribution of infill structures. For this reason, correctly predicting dimensional changes occurring during annealing presents a bigger challenge than estimating part evolution during the same process in the case of injection molded parts.

Acknowledgements: This work has been funded by University Politehnica of Bucharest, through the "Excellence Research Grants" Program, UPB - GEX 2017. Identifier: UPB-GEX-2017, 3D printing integrated system of joint parts, contract number IM 21-17-05/2017.

\section{References}

1. VASILESCU, M.D., FLESER, T., Influence of Technological Parameters on the Dimension of GEAR Parts Generated with PLA Matherial by FDM 3D Printing, Mat. Plast., 55, no. 2, 2018, p. 247-251

2. PASCU, N.E., DOBRESCU, T.G., BALAN, E., et al., Design of ABS Plastic Components through FDM Process for the Quick Replacement of Outworn Parts in a Technological Flow, Mat. Plast., 55, no. 2, 2018, p. 211-214

3. HAN, B.K., SCHNALL, M.D., OREL, S.G., ROSEN, M., Outcome of MRI-Guided Breast Biopsy, AJR Am J Roentgenol, 191 (6), 2008, pp. 1798-1804

4. KASIVISVANATHAN, V., RANNIKKO, A., BORGHI, M. et. al., MRITargeted or Standard Biopsy for Prostate-Cancer Diagnosis, N Engl J Med 2018, pp. 1767-1777

5. ZAPCIU, A., TASCA, G., AMZA, C.G., Considerations on 3D printing joints parts, ModTech 2018, IOP Conf. Series: Materials Science and Engineering 400, 2018, pp. 1-8

6. SRITHEP, Y., NEALEY, P., TURNG, L.E., Effects of annealing time and temperature on the crystallinity and heat resistance behavior of injection molded poly(lactic acid), March 2013Polymer Engineering and Science, 53(3), 2013, pp. 580-588

7. YU, L., LIU, H., XIE, F., CHEN, L., LI, X., Effect of Annealing and Orientation on Microstructures and Mechanical Properties of Polylactic Acid, April 2008, Polymer Engineering and Science, 48(4), 2008, pp. 634-641

8. ANNICCHIARICO, D., ALCOCK J. R., Review of Factors that Affect Shrinkage of Molded Part in Injection Molding Materials and Manufacturing Processes, 29(6), 2014 , pp. 662-682

9. ZHANG, Q., YAN, D., ZHANG, K., HU, G., Pattern Transformation of Heat-Shrinkable Polymer by Three-Dimensional (3D) Printing Technique, Sci Rep. 5, 2015

10. PETRESCU, H.-A., HADAR, A., PASTRAMA, S.D., Experimental Program for Impact Tests on a Honeycomb Core Composite Material, Proceedings of The Romanian Academy, Series A - Mathematics Physics Technical Sciences Information Science, 18(2), pp. 150-157, 2017

Manuscript received: 13.09 .2018 